\title{
LEAN INFORMATION MANAGEMENT: CRITERIA FOR SELECTING KEY PERFORMANCE INDICATORS AT SHOP FLOOR
}

\author{
IUGA Maria Virginia \\ Faculty of Engineering/ Department of Engineering and Management, "Lucian Blaga" University, Sibiu, \\ Romania, virginia.iuga@gmail.com \\ KIFOR Claudiu Vasile \\ Faculty of Engineering/ Department of Engineering and Management, "Lucian Blaga" University, Sibiu, \\ Romania, claudiu.kifor@ulbsibiu.ro \\ ROSCA Liviu-Ion \\ Faculty of Engineering/ Department of Engineering and Management "Lucian Blaga" University, Sibiu, \\ Romania, liviu.rosca@ulbsibiu.ro
}

\begin{abstract}
Most successful organizations worldwide use key performance indicators as an important part of their corporate strategy in order to forecast, measure and plan their businesses. Performance metrics vary in their purpose, definition and content. Therefore, the way organizations select what they think are the optimal indicators for their businesses varies from company to company, sometimes even from department to department. This study aims to answer the question of what is the most suitable way to define and select key performance indicators. More than that, it identifies the right criteria to select key performance indicators at shop floor level. This paper contributes to prior research by analysing and comparing previously researched selection criteria and proposes an original six-criteria-model, which caters towards choosing the most adequate KPIs. Furthermore, the authors take the research a step further by further steps to closed research gaps within this field of study.
\end{abstract}

Key words: KPI, lean manufacturing, shop floor, performance, waste

\section{Introduction}

Nowadays organizations place a lot of focus on not only creating scaling opportunities but also on creating and constantly increasing the performance of their units. Whether this means increasing sales performance, manufacturing performance or creating highly efficient internal processes, successful companies have long reached the conclusion that in order to reach their organizational objective and goals a performance management is indispensable. Fundamentally, a performance system points out whether the organization is going in the right direction for achieving its goals. Through measuring performance, organizations manage to establish the extent to which activities within a specific process achieve their specified goals. Mainly this happens by calculating the deviation of the actual results and the desired outcome, which is the set goal. The level of performance is mostly expressed through a quantitative standard, value or rate. Like any other system though, in order to manage and measure performance key metrics are needed. Therefore, key performance indicators (KPIs) are needed. When selecting KPIs, successful organizations ensure that these are a good fit with their competitive environment and strategy.

More and more organizations use strategically driven performance management systems that integrate actions across functional boundaries and focus on strategic results: integrated performance measurement [1]. Within the automotive industry, the performance measurement is built as a process for developing a performance direction. Thus many researchers have dedicated their research towards finding the most appropriate criteria for efficient KPI selection.

This study further concentrates on finding the best criteria for finding, selecting and implementing the optimal KPIs at shop floor. For this purpose, first it offers a preview of the best practices and criteria used to select KPIs. Therefore this paper offers a preview of the most often KPIs encountered and discussed in previous research. Moreover, the study suggests defining KPI selection criteria starting with the fundamental idea of the seven wastes. Within the third chapter, six KPI selection criteria are proposed. Further on, identified research gaps are discussed and recommendations on how to fill these gaps are provided. 


\section{Selection of optimal KPIs}

Efficient project management is the key for assuring an organization`s stability within high competitive markets. In order to increase organizational efficiency, especially informational efficiency, KPIs need to be understood and interpreted within minimal timeframes. Within lean manufacturing, KPI management is optimal when it allows the correct understanding of the shop floor situation within a minimal period of time [2]. Thus, the ideal number of selected KPIs will be low, which creates the necessity to efficiently select the most optimal KPIs. This is why many researchers have found that when selecting optimal KPIs, their validity, helpfulness and relevance for organizations are highly important criteria. Another criterion, which is a prerequisite for the active involvement of front-line employees in KPI management, lies in the fact that every area should be responsible to update those KPIs that are directly connected to their activity [3]. Further on, the process of KPI selections needs to be mapped out around a specific set of rules. Researchers have found that there are five rules that help manufacturing organizations to select the best KPIs. First of all, organizations need to focus on the critical few and not on the trivial many ones. This underlines the importance of measuring only the most important indicators, thus there will be no confusion as to what is really important. Secondly, organizations must ensure that selected KPIs drive toward their strategic intent, meaning that KPIs should measure the factors that help the organization achieve success. Third, organizations should ensure that KPIs are relatable on all levels of the organization, meaning that it is very important that production staff members from all levels relate to the metrics. Fourth, KPI data must be valid. This underlines the necessity to ensure that the measuring system is valid. It refers to the validation of the repeatability and reproducibility of the measuring system. And fifth, companies must ensure that controllable KPIs are selected, meaning that in order to obtain the strategic objectives imposed, an organization must ensure that the object of measurement is controllable [3]. Last but not least, the KPI selection criteria KPIs must be related to the strategic goals [5].

\section{Lean KPI selection criteria}

Lean management involves taking decisions based on real facts and data. Lean indicators are practically a system that allows taking decisions based on data analysis, information and objective evidence, acquired through proper methods of quantification and estimation with minimal effort, in minimal time and with minimal costs. According to Jackson, "lean management is about operating the most efficient and effective organization possible, with the least cost and zero waste" [6]. The term "waste" is used for any process that does not result in adding value to the final output or moving the process towards the final goal. The seven main wastes in production are the following: Transportation, Inventory, Motion, Waiting, Over production, Over processing and Defective parts [7]. These wastes were supplemented by another waste defined by Liker and Meyer: unused people creativity [8]. Similar to the waste types described above, waste regarding KPIs can be categorized by the same eight types. Table 1 offers a summary of these criteria. The first column lists the below mentioned waste types which set the fundament of choosing the optimal KPI selection criteria, the second and third columns give an overview of the actions and/ or criteria necessary in order to avoid waste. Within the last column, literature sources where these criteria were found are listed.

Transportation refers to the fact that information needs to be available at the closest location where it is used for operational decisions. This can be achieved through the implementation of a visual management system or through visual management techniques and methods at shop floor (A1). Moreover, the decision makers need to be closer to the production place, to Gemba, which can be achieved by keeping or bringing the employees at shop floor (A2). Lastly, distances regarding the timeframe between processing information and the moment of its use need to be avoided. This means that the information process needs to be in Gemba. In conclusion, the first selection criterion should be ease of use (EU). Organizations should select KPIs that can be processed directly in Gemba and are easy to manage.

Inventory can be referred to also as over-information. Companies need to produce and handle the minimal number of indicators, or, as mentioned above, concentrate on the critical few [9]. It is important to measure only the most effective and important indicators in order to keep the focus on what needs to me measured. The same criteria were already high lightened in previous research. Researchers emphasized on the relevance and helpfulness of a KPI for the organization and recommended to select KPIs that drive companies toward their strategic goals [10], [11], [12]. Excessive information can cause waste [13]. Therefore, a minimal number of KPIs should be selected under the consideration of their utility within process management. This criterion will hence be the utility for process management (UPM). 
In order to reduce the third type of waste, moving, KPI management should happen at shop floor. As mentioned above, this can be achieved through the selection of only those KPIs, which can be managed directly at the production place and are therefore easy to use. This waste type relates thus to the first defined criterion, EU.

Waiting refers for the time spent in waiting for a decision when shop floor nonconformities occur. Waiting often leads to waste in from of defects or defective parts. This happens due to the fact that in absence of fast decision making the only possibilities are either producing no conform part or stop the work flow until the problem is resolved. Therefore this waste type relates to the above mentioned A2, EU and UPM as in order to avoid this, organizations must have a solid KPI management and the decisional processed mapped out at shop floor level.

Over production can be associated to the organizational tendency to use an excessive number at KPIs at shop floor. Using too many indicators can slow down the processes. From a lean perspective, only the metrics that play a critical role and add value should be considered. In order to slow down processes only indicators should be selected which have a high utility for process management. Therefore the next suggested criterion is the utility for process management (UPM). In other words, organizations need to focus only on the driver indicators [14].

Over processing refers to the need to analyse the human and material efforts that flow into collecting and processing information. Therefore, important criteria consist of using the least efforts to handle data and the minimal investments in training employees to do so. Thus, the next two proposed criteria are the update time (UT) and the investments in trainings (ITR). Moreover, over processing can also lead to material resource consumption and this could translate into the need of costly investments in hardware and software needed to handle the data. Following, another criterion is the investment in hardware and software needed to process the KPIs (IHS).

The waste type defects can be translated into avoidance of KPI management mistakes. Accordingly it is highly important to select simple and comprehensible indicators that can be managed easily and in a transparent manner. Thus the next selected criterion is the familiarity of indicators (FAM).

Lastly, creativity can be associated to the involvement of front line employees in KPI management. Through front line employee involvement in the development and management of KPIs sustainability is assured due to the fact that this created acceptance of the selected and used indicators. Moreover, through the involvement of employees in the KPI processes understanding is generated. Researchers have proven that understanding has a high positive impact on organizational performance [15]. This requirement is covered through the criterion mentioned above, familiarity, which specifies the level of knowledge of these KPIs by the employees.

Therefore the proposed criteria for optimal lean KPI selections are: EU, UPM, UT, ITS, IHS and FAM. The main idea of EU is to have KPIs, which can be handled directly at the production line. The goal of UPM is to manage those KPIs that are essential for immediate decisions at shop floor. UT refers to the time needed for data to be updated. ITR and IHS refer to the investment in trainings, hardware and software needed to manage KPIs. FAM translates into the degree of accessibility of the KPIs, into how comprehensible and familiar these are for direct labor personnel.

Table 1: Proposed criteria for lean KPI selection

\begin{tabular}{|c|c|c|c|c|}
\hline Waste type & Lean-KPI management & $\begin{array}{l}\text { Directions to implement Lean } \\
\text { KPIs management }\end{array}$ & $\begin{array}{l}\mathbf{i} * / \\
\mathrm{Cj} * *\end{array}$ & $\begin{array}{l}\text { Literature } \\
\text { source }\end{array}$ \\
\hline \multirow[t]{3}{*}{ Transport } & $\begin{array}{l}\text { Have the information } \\
\text { available at the nearest } \\
\text { location where it is used for } \\
\text { operational decisions }\end{array}$ & $\begin{array}{l}\text { Implement visual management of } \\
\text { the KPIs near to the machines }\end{array}$ & 1 & \\
\hline & $\begin{array}{l}\text { Having decision staff closer to } \\
\text { the production place (Gemba) }\end{array}$ & $\begin{array}{l}\text { Implement standards: go\&see/ } \\
\text { management by } \begin{array}{l}\text { wandering } \\
\text { around etc. }\end{array}\end{array}$ & 2 & \\
\hline & $\begin{array}{l}\text { Avoid "distances" between } \\
\text { the places where the } \\
\text { information is processed /used }\end{array}$ & $\begin{array}{l}\text { Bring the processing of } \\
\text { information in Gemba }\end{array}$ & $\mathbf{U}$ & $\begin{array}{l}\text { Stamm } \quad \& \\
\text { Neitzert, } \quad 2008 \\
{[16]} \\
\text { Piatt, 2012 [17] }\end{array}$ \\
\hline $\begin{array}{l}\text { Inventory } \\
\text { (stocks) }\end{array}$ & Avoid over-information & $\begin{array}{l}\text { "Produce" and handle the } \\
\text { minimum number of indicators, } \\
\text { select the KPIs taking into }\end{array}$ & $\mathbf{P M}$ & $\begin{array}{lr}\text { Stamm } & \& \\
\text { Neitzert, } & 2008 \\
{[18]} & \\
\end{array}$ \\
\hline
\end{tabular}




\begin{tabular}{|c|c|c|c|c|}
\hline Waste type & Lean-KPI management & $\begin{array}{l}\text { Directions to implement Lean } \\
\text { KPIs management }\end{array}$ & $\begin{array}{l}\mathbf{i}^{*} / \\
\mathrm{Cj} * *\end{array}$ & $\begin{array}{l}\text { Literature } \\
\text { source }\end{array}$ \\
\hline & & $\begin{array}{l}\text { consideration the utility in } \\
\text { processes management }\end{array}$ & & $\begin{array}{l}\text { Piatt, } 2012 \quad[19] \\
\text { Jung, } 2012 \text { [20] }\end{array}$ \\
\hline Moving & $\begin{array}{l}\text { Create the possibility to } \\
\text { manage the KPIs at the } \\
\text { production place }\end{array}$ & $\begin{array}{l}\text { Select the KPIs taking into } \\
\text { consideration the possibility to be } \\
\text { managed directly at the } \\
\text { production place }\end{array}$ & $\mathbf{U}$ & $\begin{array}{lr}\text { Stamm } & \& \\
\text { Neitzert, } & 2008 \\
{[21]} & \\
\text { Piatt, 2012 [22] }\end{array}$ \\
\hline Waiting & $\begin{array}{l}\text { Having available the right } \\
\text { KPIs to drive processes }\end{array}$ & $\begin{array}{l}\text { Implement standards: go\&see/ } \\
\text { management by wandering } \\
\text { around etc. } \\
\text { Bring the processing of } \\
\text { information in Gemba } \\
\text { "Produce" and handle the } \\
\text { minimum number of indicators, } \\
\text { select the KPIs taking into } \\
\text { consideration the utility in process } \\
\text { management }\end{array}$ & $\mathbf{P M}$ & $\begin{array}{lr}\text { Stamm } & \& \\
\text { Neitzert, } & 2008 \\
{[23]} & \\
\text { Jung, 2012 } & \text { [24] } \\
\text { Piatt, 2012 [25] }\end{array}$ \\
\hline $\begin{array}{l}\text { Over- } \\
\text { production }\end{array}$ & $\begin{array}{l}\text { "Produce" only the needed } \\
\text { KPIs to manage processes }\end{array}$ & $\begin{array}{l}\text { "Produce" and handle the } \\
\text { minimum number of indicators, } \\
\text { Select the KPIs taking into } \\
\text { consideration the utility in process } \\
\text { management }\end{array}$ & $\mathbf{P M}$ & $\begin{array}{lr}\text { Stamm } & \& \\
\text { Neitzert, } & 2008 \\
{[26]} & \\
\text { Piatt, 2012 } & {[27]} \\
\text { Jung, 2012 [28] }\end{array}$ \\
\hline \multirow[t]{3}{*}{$\begin{array}{l}\text { Over- } \\
\text { processing }\end{array}$} & \multirow[t]{3}{*}{$\begin{array}{l}\text { Reduce the resources needed } \\
\text { to process the information }\end{array}$} & $\begin{array}{l}\text { Select the KPIs taking into } \\
\text { consideration the amount of } \\
\text { human activity needed }\end{array}$ & $\mathbf{T}$ & \\
\hline & & $\begin{array}{l}\text { Select the KPIs taking into } \\
\text { consideration the investments in } \\
\text { special trainings needed }\end{array}$ & TR & \\
\hline & & $\begin{array}{l}\text { Select the KPIs taking into } \\
\text { consideration the investments in } \\
\text { machines and software needed }\end{array}$ & HS & \\
\hline Defects & Avoiding data mistakes & $\begin{array}{l}\text { Select the KPIs that are familiar } \\
\text { at the shop floor and involve the } \\
\text { personnel }\end{array}$ & $\mathbf{A M}$ & $\begin{array}{l}\text { Liker \& } \begin{array}{r}\text { Meyer, } \\
2006\end{array} \\
\text { Groan et al., 2012 } \\
\text { de Leeuw \& van } \\
\text { den Berg, } 2011 \\
\text { [30] } \\
\text { Piatt, } 2012 \text { [31] }\end{array}$ \\
\hline $\begin{array}{l}\text { Not } \\
\text { involving } \\
\text { the } \\
\text { employees }\end{array}$ & $\begin{array}{l}\text { Involving the employees at } \\
\text { shop floor in KPI management }\end{array}$ & $\begin{array}{l}\text { Select the KPIs that are familiar } \\
\text { at the shop floor and involve the } \\
\text { personnel }\end{array}$ & $\mathbf{A M}$ & $\begin{array}{l}\text { Liker \& Meyer, } \\
2006 \\
\text { Groan et al., } 2012 \\
\text { [33] } \\
\text { de Leeuw \& van } \\
\text { den Berg, 2011 } \\
\text { [34] } \\
\text { Piatt, } 2012 \text { [35] }\end{array}$ \\
\hline
\end{tabular}

\section{* Direct actions}

A1: implementation of a visual management in the shop floor area

A2: bring the decision staff closer to the production place (Genchi Gembutsu)

** Criteria to select KPIs in Gemba:

EU, UPM, UT, ITS, IHS, FAM

\section{Conclusions}

The purpose of this research lied in defining the optimal criteria for KPI selection at shop floor in order to avoid "information waste" and to implement the most efficient KPIs able to lead the processes. The study builds the foundation for defining the adequate selection criteria for lean KPIs. First of all, in order to manage quality KPIs optimally, a visual management system or visual management techniques and methods need to be implemented (A1) and standards regarding the increase of the time spent by middle and top management at shop floor level needs to be increased (A2). Secondly, in addition to the two actions needed for an ideal KPI management, this paper proposed six selection criteria for 
appropriate KPIs at shop floor. These six criteria are based on the idea of avoiding waste within the management of performance indicators. Within a lean organization, indicators have to be wisely chosen so that even in small numbers they can be expressed in a comprehensible manner, quantified and measured. Also, these indicators need to be process orientated. Moreover, they have to be easy accessible and as easy to understand and manage as possible to all manufacturing operations in most departments. These criteria set the fundaments for future research. Within future research a multi-criterial analysis for the design of the shop floor performance indicators in the automotive companies will be designed. For this purpose the above mentioned and analysed criteria needs to be weighted accordingly. This research gap will be closed by the authors within future research. The research tool will consist in a questionnaire, which will be conducted within production companies in the automotive industry. This survey will target specialized personnel but also lean consultants and aim to close the gap of how these indicators are selected, perceived and managed in practice.

\section{Acknowledgement}

This work was supported by the strategic grant POSDRU/159/1.5/S/133255, Project ID 133255 (2014), co-financed by the European Social Fund within the Sectorial Operational Program Human Resources Development 2007-2013.

\section{References}

- Nanni, A. J., Dixon, J. R., Vollmann, T. E., Integrated performance measurement: management accounting to support the new manufacturing realities, Journal of Management Accounting Research, Vol. 4 No. 1, pp. 1-19, (1992).

- $\quad$ Masaaki I., Gemba Kaizen, Finmedia, Bucuresti, (2004).

- Stamm M. L., Neitzert T., Key performance indicators (KPI) for the implementationof lean methodologies in a manufavcture-to-order small and medium entreprise, School of Engineering, AUT University, Auckland, New Zealand, available at: http://aut.researchgateway.ac.nz/bitstream/handle/10292/3857/KeyperformanceindicatorsMSTN.pdf?sequen, last accessed on 23.06.14, (2008).

- Piatt, J., 5 Rules for Selecting the Best KPIs to Drive Operational Improvement, Industry week magazine, Penton Publishing, Cleveland, available at: http:/www.industryweek.com/lean-six-sigma/five-rules-selecting-best-kpisdrive-operational-improvement, last accessed on 26.03.2014, (2012).

- Jung, J.Y., Lee, J., Jung, J.n H., Kim, S. K., \& Shin, D.A., Methodology for performance measurement in manufacturing collaboration, International Journal of Industrial Engineering, Vol.19, No.3, pp. 149-160, (2012).

- Jackson, T.L., Implementing a Lean Management System, Productivity Press, Portland, (1996).

- $\quad$ Ohno T., Toyota Production System - Beyond Large-scale Production, Portland, Oregon, Productivity Press, (1988).

- $\quad$ Liker J., Meier D., The Toyota Way Fieldbook, New York, McGraw Hill, (2006).

- $\quad$ Piatt, J., 5 Rules for Selecting the Best KPIs to Drive Operational Improvement, Industry week magazine, Penton Publishing, Cleveland, available at: http://www.industryweek.com/lean-six-sigma/five-rules-selecting-best-kpisdrive-operational-improvement, last accessed on 26.03.2014, (2012).

- Stamm M. L. , Neitzert T., Key performance indicators (KPI) for the implementationof lean methodologies in a manufavcture-to-order small and medium entreprise, School of Engineering, AUT University, Auckland, New Zealand, available http://aut.researchgateway.ac.nz/bitstream/handle/10292/3857/KeyperformanceindicatorsMSTN.pdf?sequen, last accessed on 23.06.14, (2008).

- Piatt, J., 5 Rules for Selecting the Best KPIs to Drive Operational Improvement, Industry week magazine, Penton Publishing, Cleveland, available at: http://www.industryweek.com/lean-six-sigma/five-rules-selecting-best-kpisdrive-operational-improvement, last accessed on 26.03.2014, (2012).

- Jung, J.Y., Lee, J., Jung, J.n H., Kim, S. K., \& Shin, D.A., Methodology for performance measurement in manufacturing collaboration, International Journal of Industrial Engineering, Vol.19, No.3, pp. 149-160, (2012).

- Ohno, T., Toyota Production System - Beyond Large-scale Production, Portland, Oregon, Productivity Press, (1988).

- Kaplan, R.S., Norton, D.P., "The balanced scorecard: measures that drive performance." Harvard business review, Vol.83, No.7, pp. 172-180, (2005).

- De Leeuw, S., Van den Berg J., Improving operational performance by influencing shopfloor behavior via performance management practices, Journal of Operations Management, 29, No.3, 224-235, (2011).

- Stamm M. L. , Neitzert T., Key performance indicators (KPI) for the implementationof lean methodologies in a manufavcture-to-order small and medium entreprise, School of Engineering, AUT University, Auckland, New Zealand, available 
http://aut.researchgateway.ac.nz/bitstream/handle/10292/3857/KeyperformanceindicatorsMSTN.pdf?sequen, last accessed on 23.06.14, (2008).

- Piatt, J., 5 Rules for Selecting the Best KPIs to Drive Operational Improvement, Industry week magazine, Penton Publishing, Cleveland, available at: http://www.industryweek.com/lean-six-sigma/five-rules-selecting-best-kpisdrive-operational-improvement, last accessed on 26.03.2014, (2012).

- $\quad$ Stamm M. L., Neitzert T., Key performance indicators (KPI) for the implementationof lean methodologies in a manufavcture-to-order small and medium entreprise, School of Engineering, AUT University, Auckland, New Zealand, available http://aut.researchgateway.ac.nz/bitstream/handle/10292/3857/KeyperformanceindicatorsMSTN.pdf?sequen, last accessed on 23.06.14, (2008).

- $\quad$ Piatt, J., 5 Rules for Selecting the Best KPIs to Drive Operational Improvement, Industry week magazine, Penton Publishing, Cleveland, available at: http://www.industryweek.com/lean-six-sigma/five-rules-selecting-best-kpisdrive-operational-improvement, last accessed on 26.03.2014, (2012).

- Jung, J.Y., Lee, J., Jung, J.n H., Kim, S. K., \& Shin, D.A., Methodology for performance measurement in manufacturing collaboration, International Journal of Industrial Engineering, Vol.19, No.3, pp. 149-160, (2012).

- Stamm M. L. , Neitzert T., Key performance indicators (KPI) for the implementationof lean methodologies in a manufavcture-to-order small and medium entreprise, School of Engineering, AUT University, Auckland, New Zealand, available at: http://aut.researchgateway.ac.nz/bitstream/handle/10292/3857/KeyperformanceindicatorsMSTN.pdf?sequen, last accessed on 23.06.14, (2008).

- Piatt, J., 5 Rules for Selecting the Best KPIs to Drive Operational Improvement, Industry week magazine, Penton Publishing, Cleveland, available at: http://www.industryweek.com/lean-six-sigma/five-rules-selecting-best-kpisdrive-operational-improvement, last accessed on 26.03.2014, (2012).

- Stamm M. L. , Neitzert T., Key performance indicators (KPI) for the implementationof lean methodologies in a manufavcture-to-order small and medium entreprise, School of Engineering, AUT University, Auckland, New Zealand, available http://aut.researchgateway.ac.nz/bitstream/handle/10292/3857/KeyperformanceindicatorsMSTN.pdf?sequen, last accessed on 23.06.14, (2008).

- Jung, J.Y., Lee, J., Jung, J.n H., Kim, S. K., \& Shin, D.A., Methodology for performance measurement in manufacturing collaboration, International Journal of Industrial Engineering, Vol.19, No.3, pp. 149-160, (2012).

- $\quad$ Piatt, J., 5 Rules for Selecting the Best KPIs to Drive Operational Improvement, Industry week magazine, Penton Publishing, Cleveland, available at: http://www.industryweek.com/lean-six-sigma/five-rules-selecting-best-kpisdrive-operational-improvement, last accessed on 26.03.2014, (2012).

- $\quad$ Stamm M. L. , Neitzert T., Key performance indicators (KPI) for the implementationof lean methodologies in a manufavcture-to-order small and medium entreprise, School of Engineering, AUT University, Auckland, New Zealand, available at: http://aut.researchgateway.ac.nz/bitstream/handle/10292/3857/KeyperformanceindicatorsMSTN.pdf?sequen, last accessed on 23.06.14, (2008).

- Piatt, J., 5 Rules for Selecting the Best KPIs to Drive Operational Improvement, Industry week magazine, Penton Publishing, Cleveland, available at: http://www.industryweek.com/lean-six-sigma/five-rules-selecting-best-kpisdrive-operational-improvement, last accessed on 26.03.2014, (2012).

- Jung, J.Y., Lee, J., Jung, J.n H., Kim, S. K., \& Shin, D.A., Methodology for performance measurement in manufacturing collaboration, International Journal of Industrial Engineering, Vol.19, No.3, pp. 149-160, (2012).

- $\quad$ Liker J., Meier D., The Toyota Way Fieldbook, New York, McGraw Hill, (2006).

- Groen B., Marc Wouters, M., Wilderom, C., Why do employees take more initiatives to improve their performance after co-developing performance measures? A field study, Elsevier, Management Accounting Research, pp. 120141, (2012).

- Piatt, J., 5 Rules for Selecting the Best KPIs to Drive Operational Improvement, Industry week magazine, Penton Publishing, Cleveland, available at: http://www.industryweek.com/lean-six-sigma/five-rules-selecting-best-kpisdrive-operational-improvement, last accessed on 26.03.2014, (2012).

- $\quad$ Liker J., Meier D., The Toyota Way Fieldbook, New York, McGraw Hill, (2006).

- Groen B., Marc Wouters, M., Wilderom, C., Why do employees take more initiatives to improve their performance after co-developing performance measures? A field study, Elsevier, Management Accounting Research, pp. 120141, (2012).

- De Leeuw, S., Van den Berg J., Improving operational performance by influencing shopfloor behavior via performance management practices, Journal of Operations Management, 29, No.3, 224-235, (2011).

- $\quad$ Piatt, J., 5 Rules for Selecting the Best KPIs to Drive Operational Improvement, Industry week magazine, Penton Publishing, Cleveland, available at: http://www.industryweek.com/lean-six-sigma/five-rules-selecting-best-kpisdrive-operational-improvement, last accessed on 26.03.2014, (2012). 